\title{
Naso-facial anthropometric study of Female Sikkimese University Students
}

\author{
Dr. M N Chettri ${ }^{1,}$ Dr P Sinha ${ }^{2}$ Dr S Chakraborty ${ }^{3}$,Dr H Jain ${ }^{4}$ \\ ${ }^{1} M B B S$, MS Ent, Assistant Professor Of Ent, SMIMS, Gangtok, Sikkim, India. \\ ${ }^{2}$ MBBS, Msc Anatomy, Assoc Professor Of Anatomy, SMIMS, Gangtok, Sikkim, India. \\ ${ }^{3}$ MBBS, MS, MAMS, FICS, Professor \& Head Ent, SMIMS, Gangtok, Sikkim, India. \\ ${ }^{4}$ MBBS, Junior Resident, Ent, SMIMS, Gangtok, Sikkim, India.
}

\begin{abstract}
:
Background:The face and nasal dimensions are most important cephalometric parameters describing human morphology. Nose is the most important aesthetic unit of face. There is wide variation in size and shape of nose and face due to ethnic influences. Nasal and Facial Index can be used to into various categories.

Method:Prospective study undertaken by the department of Otorhinolaryngology, Sikkim Manipal Institute of Medical Sciences, Gangtok after taking Institutional Ethical Committee clearance over a period of 1 year in ethnic femalesof Sikkim between the ages of 17-25yrs.

Results:The average Nasal Index was found to be 70.7 with majority being leptorhine.Average Facial Index was calculated to be 103.1, majority were hyperleptoproscopic. Further analysis were done on basis of ethnicity.

Conclusion:This study is an effort to group the naso-facial measurements of female of Sikkim.

Keywords: Anthropometry; Nasal Index; Facial Index; Sikkim; Ethnicity
\end{abstract}

\section{Introduction}

The face and nasal dimensions are the most important cephalometric parameters that describe human morphology. The nose is one of the most important aesthetic units of the face [1]. There is a wide variation in the size and shape of the nose and ethnic influences can result in different appearance of the nose [2]. The nose has been attributed to natural selection in human evolution, the cold and dry climates having narrower noses while the warm and moist climates have broader noses [4]. Nasal elongation is also said to be influenced by adaptation to environment [5]

Morphologically the human nose can be classified into Roman or aquiline nose, the Greek or straight nose, the Nubian nose, the hawk nose, the snub nose and the celestial or turn up nose [6]

The human nose canalso be classified using the nasal index. The nasal index is a ratio of the nasal width to the nasal length multiplied by 100 [4]. It is an ethnic sensitive anthropometrical index [7] and has become a useful tool in forensic science [8].

Williams et al [9] has grouped the human nose using the nasal index. The human nose can be grouped into three classes, the leptorrhine (long and narrow nose), the mesorrhine (medium) and the platyrrhine (broad nose) nose types using the nasal index. A nose type is said to be leptorrhine if the nasal index is 69.9 or less, mesorrhine if the nasal index is between 70-84.9 and platyrrhine if the nasal index is 85 and above.

There is a very strong correlation between the nasal index and absolute humility [10] meaning that in a moist climate, the nasal index is high. Farkas et al., [11] has also documented that nasal index is related to regional and climatic differences.

The human face type can be classified into the following types according to the facial Index, which is a ratio of the facial width to the facialheight multiplied by 100.According to Wiliams et al [9] there are five categories of face based on the facial index namely: hyper euryproscopic (very broad, short face with Facial Index <80), Euryproscopic (broad, short face with Facial Index 79.0-83.9), Mesoproscopic (normoprospic, average face with Facial Index 84.0-87.9), Leptoproscopic (tall, narrow face with facial Index 88.0-92.9) and hyperleptoproscopic (very tall, narrow face with Facial Index >=93).

Sikkim, a state in the Republic of India is a multi-ethnic state. The ethnic groups comprise of the Lepchas, the Bhutias, the Sherpas and the Nepalese. [12]

This study is an effort to group the naso-facial measurements of the female University Students of the state of Sikkim and compare it with the national referencenaso-facial measurements of various ethnic groups. This will enable the Rhinoplastic and Reconstructive Surgeon in understanding the naso-facial morphology of the studied population and plan any reconstructive surgeries likewise.

To treat congenital, post-traumaticfacial disfigurements in members of these groups,surgeons require access to craniofacial databasesbased on accurate anthropometric measurements [13] 


\section{Materials And Methods}

Setting:The study was done by the Department of Otorhinolaryngology, Sikkim Manipal Institute of Medical Sciences, Tadong, Gangtok in collaboration with other constituents of the Sikkim Manipal University.

Ethical Clearance: Institutional Ethical Committee clearance was taken prior to commencement of study.Written Informed consent has been taken from the subjects before including the subject.

Study design: It is a prospective descriptive design.

Study period: It was for a period of 1 calendar year

Study population: Ethnic Female Sikkim Population between the ages of 17-25 during the study periods attending Sikkim Manipal University was considered as subjects for the study. Sampling was non randomized convenience sampling

Sample size: All eligible candidates during the study period.

Inclusion Criteria: SMU Female Students between 17-25 years

Exclusion Criteria: Students not willing to give consent.

Students having $\mathrm{h} / \mathrm{o}$ or evidence of facial injury affecting the nose

Students having undergone prior septo- rhinoplasticpreocedures.

Study variables: Demographical data including the age, origin, duration of stay in the land of origin, parental and grandparental origin.

Measurements of nasal and facial length and width.

Procedures: The subjects was made to sit comfortably on a chair with the head held out straight in the anatomical position. The nasal length and nasal width will be measured in centimeters using spreading calipers. The nasal length is measured as the straight distance from the nasion to the subnasale, while the nasal width is measured at the nasal base from ala to ala. Each measurement was taken twice and the average taken. The nasal index is then calculation by dividing the nasal width by the nasal length and multiplying by 100.The facial height is measured as the straight distance from the nasion to the gnathion, while the facial width is measured fromzygion to zygion. Each measurement was taken twice and the average taken. The facial index is then calculation by dividing the facial width by the facial height and multiplying by $100[14]$.

\section{Results}

There was a total of 192 female students included in the study. The average age of the subjects was 19.5 years with a range of $17-22$.

East District had121 subjects accounting for $63.02 \%$, West District had 32 subjects accounting for $16.67 \%$, South District accounted for $16.14 \%$ of cases with 31 subjects whereas the North District accounted for only $4.17 \%$ of the sample with 8 subjects.

Community wise Nepali with 148 subjects comprised $77.08 \%$ of the sample, Bhutias with 24 subjects $12.5 \%$, Lepchas with 14 samples formed $7.3 \%$ whereas Sherpas were only 6 subjects contributing $3.1 \%$ of the sample size.

The average Nasal Index was found to be 70.7 with a Standard Deviation \pm 18.35 minimum being 50 and maximum being 96.20. Classified on the Nasal Index 95 subjects were found to be Leptorrhine with an average NI of 63.82, 87 as Mesorrhine with an average NI of 75.8 and the remainder 10 as Platyrrhine with an average NI of 90.4

The average Facial Index was calculated to be with a 103 .1Standard Deviation of \pm 12.65 and a minimum value of 83.2 and maximum of 152.17 . The majority of the sample was hyperleptoproscopic with 154 subjects and an average facial index (FI) of 106.7. 21, 13 and 4 subjects were found to be Leptoproscopic, Mesoproscopic and Euryproscopic type with average facial indexes being 90.4, 86. and 83.4 respectively. Hypereuryproscopic type of facial structurewas not encountered

The tablesI\&II shows the community wise distribution of Nasal \& Facial Type

Nepali young adult's majority had facial index of $106.2 \pm 5.53$ and nasal index of $64.2 \pm 18.35$, implying hyperleptoproscopic face type and leptorrhine nose type. Facial index of Bhutia young adults showed $107.5 \pm 12.67$ with nasal index of $62.1 \pm 5.87$, indicating the dominance of the hyperleptoproscopic face type and Leptorrhine nose type. Lepcha young adults revealed facial index and nasal index of $103.4 \pm 8.8$ and $76.0 \pm$ 8.6, respectively. They had hyperleptoproscopic face type and Mesorrhine nose type. The nasal index of the Sherpa is Mesorrhine $80.2 \pm 5.5$ and facial index is hyperleptoproscopic $119.5 \pm 12.6$

\section{Statistical Analysis}

Data was entered in SPSS 16.0 and descriptive and analytical statistics were used. The Paired-Samples T Test procedure was used to compares the means of two variables for a single group in each case. The Sig. (2tailed) column displayed the probability of obtaining a t statistic whose absolute value was equal to or greater 
than the obtained $t$ statistic. The confidence interval was taken to be $95 \%(0.05)$ and all values were found to be statistically significant.

Paired Samples Correlationsbetween Nasal_Index\&Facial_Index was found to be 0.223 with a sigma value of 0.001. (Table III).

\section{Discussion}

Theracial and ethnic morphometric differences in the nasalergonomics in the world population have been thefocus of investigation [11]. The size, shape andproportion of the nose is very valuable for cosmeticand plastic surgeons, undertaking repair and reconstruction of the nose [15]. Present studydemonstrated that there were racial dimorphism in nasal ergonomics. Several studiesshowed sexual differences in NL, NB, NH and CI. [16] Thestudy conducted by Milgrim also showed that therewere racial differences in nasal breadth [17]. Theyfound the mean nasal breadth of white females was $31 \mathrm{~mm}$ and South American females $34.4 \mathrm{~mm}$.

Compared to a study on Facial Index as seen at the University of Ilorin Teaching Hospital (UITH), Ilorin Nigeria [18] the type of face structure was Euriprosopic face shape (72\%), Mesoprosopic (14\%), Leptoprosopic (9\%), Hypereuriprosopic (5\%) and Hyperleptoprosopic (0\%) whereas in our study the majority of the sample was hyperleptoproscopic with 114 subjects and an average facial index (FI) of 107.9. 12, 6 and 4 subjects were found to be Leptoproscopic, Mesoproscopic and Euryproscopic type with average facial indexes being 90.4, 86.7 and 83.2 respectively. Hypereuryproscopic type of facial structure was not encountered in our study.

According to another study on university students from Malayasia [19] themeanfacial index of Malay subjects showed $88.82 \pm 6.63$ with nasal index of $81.00 \pm 7.48$, showing dominance of the leptoprosopic facetype andmesorrhine nose type. Chinese subjects showed facial index and nasal index of $85.65 \pm 6.50$ and $79.56 \pm 8.62$, respectively, having mesoprosopic face type andmesorrhine nose type. Indian students had facial index of $92.57 \pm 7.19$ and nasal index of $76.27 \pm 7.39$, having leptoprosopic face type andmesorrhine nose type in that study.

In a study of Bhasin M.K [20], Nepalese dominant facial type was mesoproscopic but in our study the Sikkimese Nepalese predominantly had hyperleptoproscopic which is quite opposite in our study.

In the case of morphological facial index, the types of faces vary among the people of Indian states where people of Madhya Pradesh are Mesoprosopic [21], people of Bengal and Assam are Euryprosopic [22,23], people of Rajasthan are Hyperleptoprosopic [24], and people of Maharashtra [25] Gujarat are Leptoprosopic[26] and Sikkim are hyperleptoproscopic (present study). The values of the index for the population of other different countries make the people of Arab Mesoprosopic [27], people of Persia and Australia Hypereuryprosopic [28] and Malaysian Indians Mesoprosopic [29].

There are characteristic differences among populations in the shape and the size of the nose; it is likely that the nasal bone and the piriform aperture also have some differences, which can provide useful insights for the population affinity in anthropology. The nasal index is highly depending on the temperature of that region. This index distinctively differs from other anthropological indices, in being based upon both bony and cartilaginous landmarks. Anthropological studies suggest that climatically influenced selection acts to increase the efficiency of the nose in both warming and moistening of inspired air [30]. As such, in colder and drier climates, the length of the nasal passage is increased and the base is narrowed, thus increasing the surface area and the period of time over which inspired air is warmed and moistened. So the warmer regions of India e.g. South Indians have very broad noses (Hyperchamaerhinae). On the other hand in North India, where temperature is moderate to high, have medium to broad noses (Chamaerhinae). People of Gujarat] are Mesorhinae. People of Sikkim present study are predominantly leptorrhine. The Nigerian population (warm region) is reported to have the broad nose to very broad nose [31]. The Indian Negroids also have broad nose (Hyperchamaerhinae) [33].

Several studies have indicated the racial and ethnic differences in nasal index amongst different populations [34]. Most Caucasians are leptorrhine having long and narrow nose with nasal index of 69.9 or less. The Indo-Aryan was also similar to the Europeans, possessing a fine nose [35]. Jingpo people in China are mesorrhine [36]. Indo-African [35] and Afro-American [37] people have platyrrhine nose type [38].

Kaushal et al. [39] stated that nasal index of a race appears to be markedly related to climate; the narrow and long noses favored cold and dry climate, as there was more surface area for warming the air, whereas flat and broad nose types were seen in warm and moist climate, as a consequence of natural selection in human evolution [40].

P Sinha et al[41] in a study on craniofacial anthropometry in newborns of Sikkimese origin in 2014 found the mean prosopic index percentages for male and female newborns in Sikkim were 100.02 and 97.26 respectively. This indicated a hyperleptoproscopic skull which is the same as in our study

More similar studies with a larger and varied sample size and ethnic concentration from the region are required to authenticate the values obtained. 


\section{Summary}

- People of Sikkim in present study are predominantly leptorrhine and hyperleptoproscopic.

- Nepali young adult's majority hyperleptoproscopic face type and leptorrhine nose.

- Bhutia's dominant hyperleptoproscopic face type and Leptorrhine nose type.

- Lepcha young adults had hyperleptoproscopic face type and Mesorrhine nose type.

- Sherpa's areMesorrhineand hyperleptoproscopic

\section{Acknowledgements}

I would like to acknowledge the administration of the constituent colleges of SMU for allowing us to conduct the study.

Financial Support:"This research received no specific grant fromany funding agency, commercial or notforprofitsectors."

Ethical Standards:The authors assert that all procedures contributing to this work comply with the ethical standards of the relevant national and institutionalguidelines on humansubjects and with the Helsinki Declaration of 1975, as revised in 2008. Institutional Ethical clearance sought and approved.

\section{References}

[1]. Powell N, Homphresy B. Proportion of aesthetic face. Theme-Stratton, New York, 1984.

[2]. Heidari Z, Mahmoudzadeh HS et al. Anthropometric measurement of the external nose in 25-year old Sistani and Baluch aborigine women in the South-West Iran. Folio morphology, 68 (2), 2009, 88-92.

[3]. Indira B, Sharma JC. The Nose in relation to Head and face - An anthropometric study. Indian J. of Otolaryngology and Head and Neck surgery, 11(4), 1959.

[4]. Hall RL, Hall DL. Geographic variation of native people along the pacific coast. Hum. Biol., 67(3), 1995, 407-26.

[5]. Daniel B. Racial anthropology and genetics of the Lebanese. Available in www.nasalindexoflebanese.com.2002,1-2.

[6]. Kashmira L. Different types of Noses, 2011. Available in: http://www.buzzle.com/articles/diferent-types-of-noses.html.

[7]. StakE G, Dragidella f et al. Anthropometric studies of nasal index of the Kosovo Albanian population. Antrocom Online Journal of Anthropology, 8(2), 2012, 457-62.

[8]. Xu B, Wang Y et al. A computer-aid study on the craniofacial features of Archang race in Yunnan Province of China. Hua Xi Qiang Yi XueZaZhi, 19 (6), 2011, 394-6.

[9]. Williams P, Dyson M, et al Skeletal system. Gray’s Anathomy, 38th Ed., Churchill Livingstone, Edinburgh, 1995, 609-12.

[10]. Weiner JS. Nose shape and climate. American Journals of Phys. Anthrop., 12, 1954, 615-8.

[11]. Farkas LG, Kolar IR, et al Abstract of geography of the nose, a morphometric study. Aesth. Plast. Surg., 10 (4), 1986, 191-223.

[12]. Demographic Features of the State of Sikkim, Home Department Govt. of Sikkim, available at http://sikkim.nic.in/homedept/demog.htm accessed on 6th November 2014

[13]. Koirala S, Shah S,BaralP. A Comparative Anthropometric Study of Mongoloid and Tharu Ethnic Races in Eastern Nepal. WebmedCentral ANATOMY 2012;3(6):WMC003512

[14]. Romo T, Abraham MT. The Ethnic Nose. Facial Plast. Surg., 19(3), 2003, 269-78.

[15]. Ahmet Uzun, HayatiAkbas, SaitBilgic, Mehmet Emirzeoglu, OzgurBostanci, BunyaminSahin, YukselBek. The average values of the nasal anthropometric measurements in 108 young Turkish males. AurisNasus Larynx 2006; 33:31-5.

[16]. Schimittbuhl M, Le Minor JM. New approaches to human facial morphology using automatic quantification of the relative position of the orbital and nasal apertures. SurgRadiolAnat 1998; 20: 321-7.

[17]. Milgrim LM, Lawson W, Cohen AF. Anthropometric analysis of the female Latino nose. Revised aesthetic concepts and their surgical implications. Arch Otolaryngol Head, Neck Surg 1996 122: 1079-86.

[18]. Stephen AO, Folu EO, Adekunle DD, Ismaila AL: Facial Index as seen at the University of Ilorin Teaching Hospital (UITH), Ilorin Nigeria. Asian Journal of Multidisciplinary Studies 2014;2(5) 20-22

[19]. Wai M M et al, Nasofacial Anthropometric Study among University Students of Three Races in Malaysia Hindawi Publishing Corporation Advances in Anatomy Volume 2015, Article ID 780756, 5 pages accessed from http://dx.doi.org/10.1155/2015/780756

[20]. Bhasin MK. Genetics of castes and tribes of India. Int J Hum Genet 2006; 6(3):233-74.

[21]. I. Bhargava, G. Kher, A comparative study anthropometric study of Bhils and Barelas of Central India, J. Anat. Soc. India 10 (1961) 26-33.

[22]. A. Basu, Anthropometry of the Kayasthas of Bengal, J. Anat. Soc. India 12 (1963) 20-25.

[23]. S. Gupta, Physical Anthropology of Koch Population of India: A Study of Assam, Mittal Publications, New Delhi, 1993.

[24]. R. Mani, Comparative study of facial index of Rajput community of Bikaner district of Rajasthan and other communities and races, Asian J. Biol. Pharm. Sci. 3 (20) (2013) 5-7.

[25]. D. Howale, R. Pradhan, L. Jain, R. Lekharu, The calculation of various craniofacial indices in Maharastra population, Int. J. Curr. Res. 4 (8) (2012) 162-166.

[26]. M. Mehta et al. / Journal of Forensic Radiology and Imaging 2 (2014) 64-71

[27]. C. Coon, The Races of Europe, Macmillan and Co., New York, 1939.

[28]. J. Firmin, The Equality of Human Race-Anthropological Papers, 1966

[29]. W. Ngeow, Staljunid, craniofacial anthropometric norms of Malaysian Indians, Indian J. Dent. Res. 20 (2009) 313-319.

[30]. I. Bhargava, J. Sharma, Anthropometric study of Barelas of Madhya Pradesh, J. Anat. Soc. India 8 (1959) $43-44$.

[31]. R. Karambelkar, A. Shewale, R. Karambelkar, B. Umarji, Comparison of nasal morphology between Southern and Northern India, Anat. Karnataka 7 (1) (2013) 26-30.

[32]. S. Adebisi, Sex identification from the skull of the Hausa/Fulani in Northern Nigeria, Ann. Afr. Med. 2 (1) (2003) $22-26$.

[33]. H. Risely, The People of India, 2nd edition, Thacker, Spink \& Co., Calcutta, 1915 [9] G.S. Oladipo, H.B. Fawehinmi, Y.A Suleiman, The study of nasal parameters (nasal height, nasal width, nasal index), amongst the Yorubas of Nigeria, Internet J. Biol. Anthropol. 2 (3) (2009), http://dx.doi.org/10.5580/10c0.

[34]. G. S. Oladipo, A. O. Olabiyi, A. A. Oremosu, and C. C. Noronha, "Nasal indices among major ethnic groups in southern Nigeria," Academic Journals, Scientific Research and Essay, vol. 2, no. 1, pp. 020-022, 2007 
[35]. C. Z. Sparks and R. L. Jantz, "A reassessment of human cranial plasticity: boas revisited," Proceedings of the National Academy of Sciences of the United States of America, vol. 99, no. 23, pp. 14636-14639, 2002

[36]. B. Xu, Y. Wang, J. Ma, M. Li, and L. Xu, "A computer-aid study on the craniofacial features of archang race in Yunnan province of China," HuaxiKouqiangYixueZazhi, vol. 19, no. 6, pp. 394-396, 2001

[37]. F. A. Ofodile, "Nasal bones and pyriform apertures in blacks," Annals of Plastic Surgery, vol. 32, no. 1, pp. 21-26, 1994

[38]. V. R. Shetti, S. R. Pai, G. K. Sneha, C. Gupta, and P. Chethan, "Study of prosopic (Facial) index of Indian and Malaysian students," International Journal of Morphology, vol. 29, no. 3, pp. 1018-1021, 2011

[39]. S. Kaushal, V. V. G. Patnaik, and P. Kaur, "Somatometric analysis of nasal morphology in the endogamous groups of Punjab," Human Biology Review, vol. 2, no. 1, 2013

[40]. G. S. Oladipo, M. A. Eroje, and H. B. Fahwehinmi, "Anthropometric comparison of nasal indices between Andoni and Okrika tribes of Rivers State, Nigeria,” International Journal of Medicine and Medical Sciences, vol. 1, no. 4, pp. 135-137, 2009

[41]. P Sinha, B K Tamang, S Chakraborty Craniofacial anthropometry in newborns of Sikkimeseorigin; The Journal of Laryngology \& Otology (2014), 128, 527-530.

Table Ishowsthe community wise distribution of Nasal Type

\begin{tabular}{|c|c|c|c|c|c|c|c|c|c|c|}
\hline \multirow{3}{*}{$\begin{array}{l}\text { Community } \\
\text { Distribution }\end{array}$} & \multicolumn{10}{|c|}{ Nasal Index } \\
\hline & \multirow{2}{*}{ 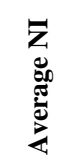 } & \multirow{2}{*}{$\frac{\vec{\Xi}}{\stackrel{\Xi}{\Xi}}$} & \multirow{2}{*}{ 志 } & \multirow{2}{*}{ 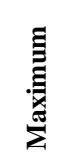 } & \multicolumn{2}{|c|}{$\mathbf{L}$} & \multicolumn{2}{|c|}{$\mathbf{M}$} & \multicolumn{2}{|c|}{$\mathbf{P}$} \\
\hline & & & & & $\mathbf{n}$ & avg & $\mathbf{n}$ & avg & $\mathbf{n}$ & avg \\
\hline Nepali & 70.52 & 18.10 & 50 & 96.2 & 76 & 64.2 & 62 & 75.6 & 10 & 90.4 \\
\hline Bhutia & 68.6 & 5.81 & 59.6 & 96.2 & 11 & 62.1 & 13 & 76.1 & - & - \\
\hline Lepcha & 70.6 & 8.6 & 56.6 & 96.2 & 6 & 65.1 & 8 & 76.0 & - & - \\
\hline Sherpa & 74.0 & 5.5 & 61.7 & 83.7 & 2 & 61.7 & 4 & 80.2 & - & - \\
\hline
\end{tabular}

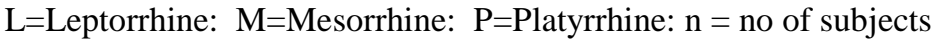

\begin{tabular}{|c|c|c|c|c|c|c|c|c|c|c|c|c|}
\hline \multirow{3}{*}{$\begin{array}{l}\text { Commu } \\
\text { nity } \\
\text { Distribut } \\
\text { ion }\end{array}$} & \multicolumn{12}{|c|}{ FacialIndex } \\
\hline & \multirow{2}{*}{ 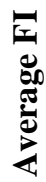 } & \multirow{2}{*}{$\frac{\overrightarrow{0}}{\tilde{0}}$} & \multirow{2}{*}{ 鸹 } & \multirow{2}{*}{ 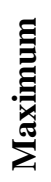 } & \multicolumn{2}{|c|}{ EP } & \multicolumn{2}{|c|}{$\mathbf{M P}$} & \multicolumn{2}{|c|}{ HLP } & \multicolumn{2}{|c|}{$\mathbf{L P}$} \\
\hline & & & & & $\mathbf{n}$ & avg & n & avg & $\mathbf{n}$ & avg & $\mathbf{n}$ & avg \\
\hline Nepali & $\begin{array}{c}10 \\
3 . \\
3\end{array}$ & $\begin{array}{l}5 . \\
53\end{array}$ & $\begin{array}{c}83 \\
.2\end{array}$ & $\begin{array}{c}15 \\
2 . \\
2\end{array}$ & 2 & 83.7 & 9 & 86.3 & 119 & $\begin{array}{c}106 . \\
2\end{array}$ & 18 & $\begin{array}{c}90 . \\
5\end{array}$ \\
\hline Bhutia & $\begin{array}{c}10 \\
2 . \\
9\end{array}$ & $\begin{array}{c}12 \\
.6 \\
7\end{array}$ & $\begin{array}{c}83 \\
.2\end{array}$ & $\begin{array}{l}15 \\
2 . \\
2\end{array}$ & - & - & 2 & 86.6 & 19 & $\begin{array}{c}107 \\
5\end{array}$ & 3 & $\begin{array}{c}90 . \\
0\end{array}$ \\
\hline Lepcha & $\begin{array}{c}10 \\
3 . \\
0\end{array}$ & $\begin{array}{l}8 . \\
8\end{array}$ & $\begin{array}{c}83 \\
.2\end{array}$ & $\begin{array}{c}12 \\
0 . \\
1\end{array}$ & 2 & 83.2 & - & - & 12 & $\begin{array}{c}103 . \\
4\end{array}$ & - & - \\
\hline Sherpa & $\begin{array}{c}10 \\
9\end{array}$ & $\begin{array}{r}12 \\
.6\end{array}$ & $\begin{array}{r}87 \\
.9\end{array}$ & $\begin{array}{c}12 \\
9 . \\
1\end{array}$ & - & - & 2 & 87.9 & 4 & $\begin{array}{c}119 . \\
5\end{array}$ & - & - \\
\hline
\end{tabular}

Table II showsthe community wise distribution of Facial Type

Euryproscopic $=$ EP, Mesoproscopic=MP, Hyperleptoproscopic HLP, Leptoproscopic LP

Paired Samples Test

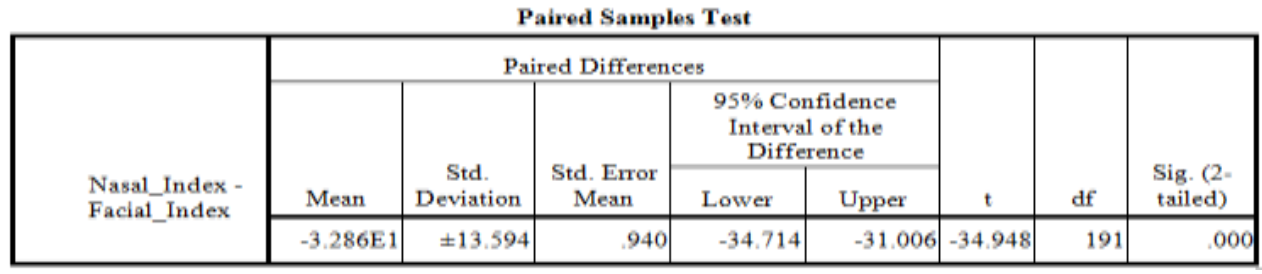


Table III

LEGEND

Table Ishowsthe community wise distribution of Nasal Type

Table II showsthe community wise distribution of Facial Type

Table IIIshows Paired Samples Test

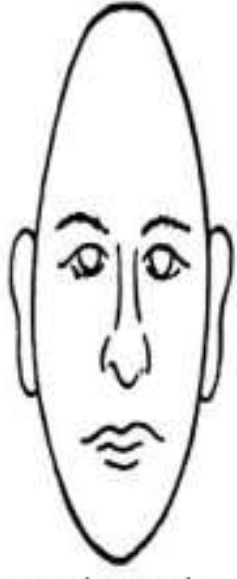

Hyperleptoprosopic

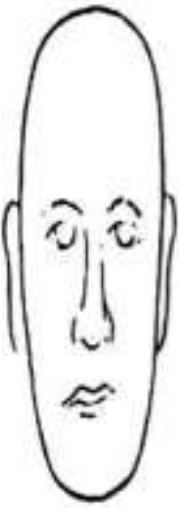

Leptoprosopic,

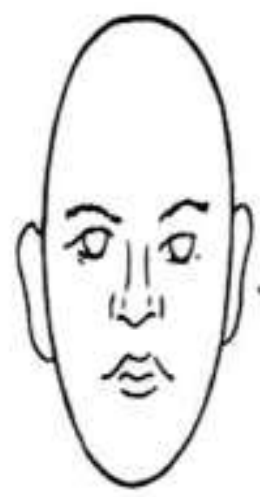

Mesoprosopic,

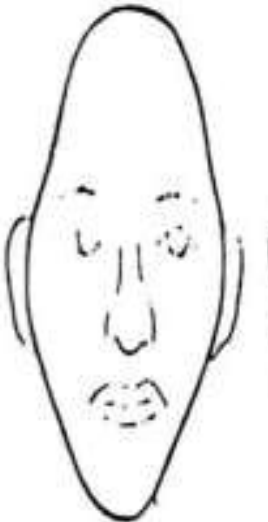

Euriprosopic

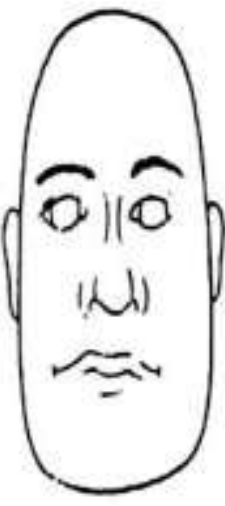

Hypereuriprosopic 